MATEC Web of Conferences 19, 01008 (2014)

DOI: $10.1051 /$ matecconf/ 20141901008

(C) Owned by the authors, published by EDP Sciences, 2014

\title{
Heat loss of heat pipelines in insulation moisture conditions with the evaporation
}

\author{
Vyacheslav Yu. Polovnikov and Ekaterina V. Gubina \\ National Research Tomsk Polytechnic University, 634050 Tomsk, Russia
}

\begin{abstract}
Results of numerical simulation of heat and mass transfer in a wet fibroporous material in conditions of evaporation and steam diffusion were obtained. Values of heat and mass fluxes were established. The contribution of evaporation effect to total heat flux and need to consider volume fractions of water and steam into the structure of fibroporous material in calculation of effective thermal conductivity were shown. Nonstationarity of heat and mass transfer in conditions of considered problem can be ignored.
\end{abstract}

\section{Introduction}

An intensity of heat and mass transfer processes in a wet thermal insulation is an important problem when choosing a specific type of insulation for thermal protection of various objects, working in different conditions. The largest contribution to the change of thermal conditions makes a change of thermal conductivity of thermal barrier material in wetting conditions [1-3]. One more important factor is a moisture evaporation $[4,5]$ and a mass transfer [6].

Mathematical models [4] and approaches to analysis of effective thermal conductivity [1-3] are difficult. Therefore, we must create a relatively simple method of analysis of thermal regimes of thermal protection of objects, working in difficult conditions.

The aim of the present paper is a mathematical modeling of thermal regimes and numerical analysis of heat fluxes in a wet fibroporous material in conditions of evaporation and steam diffusion.

\section{Problem statement}

We consider a cylindrical layer of the wet fibroporous material to be fixed to the surface of a metal pipe (Fig. 1). The initial values of temperature and humidity in the domain of solutions (Fig. 1) have constant values. The internal surface of the pipe $R_{1}$ (Fig. 1) has a constant temperature and at the boundary between the metal tube wall - the wet fibroporous material $R_{2}$ moisture evaporates. The generated steam diffuses through the layer of the wet fibroporous material in a direction toward the external surface $R_{3}$. The moisture and the steam are the reasons for of changing the effective thermal conductivity of the wet fibroporous material and mass flux on the external surface of the wet fibroporous material changes the mechanisms of heat and mass transfer to the external environment.

For the domain under consideration (Fig. 1) we solve a 1D nonlinear and nonstationary problem of heat and mass transfer in a wet fibroporous material in conditions of evaporation and steam diffusion.

${ }^{\text {a }}$ Corresponding author: polov@tpu.ru

This is an Open Access article distributed under the terms of the Creative Commons Attribution License 4.0, which permits unrestricted use, distribution, and reproduction in any medium, provided the original work is properly cited. 


\section{MATEC Web of Conferences}

Formulating the problem, we used the following assumptions:

1. The heat transfer processes in the internal and the external environment are disregarded.

2. Thermophysical characteristics of materials used in the analysis are constant and known values.

3. There is an ideal thermal contact conditions at the boundary between the metal tube wall - the wet fibroporous material.

4. The heat in the metal tube wall and the layer of wet fibroporous material is transferred only by conduction.

The listed assumptions, on the one hand, do not impose constrains of principle on the physical model of the system (Fig. 1), but, on the other hand, allow one to simplify in a certain manner the algorithm and method for solving the posed problem.

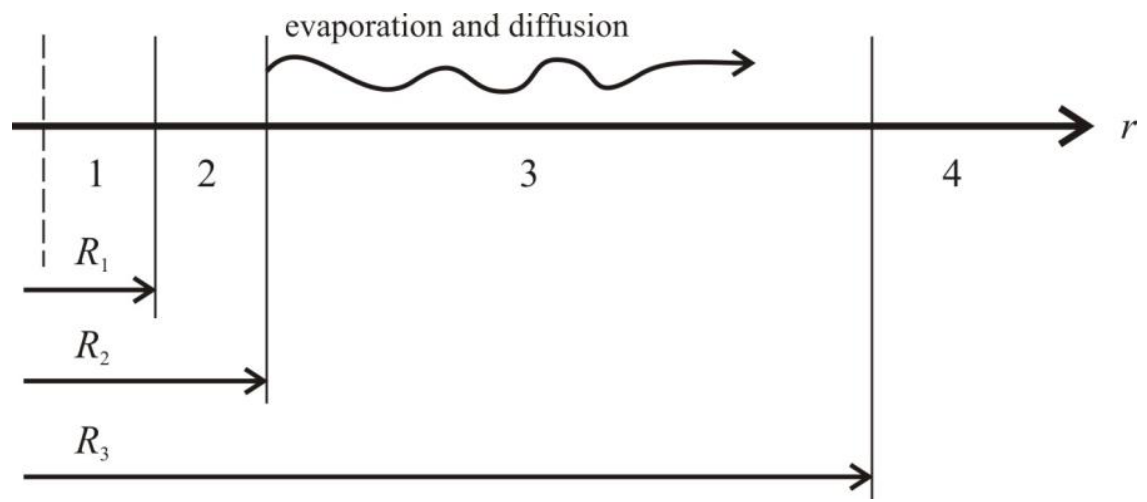

Figure 1. A scheme of decision domain: 1 - internal environment; 2 - metal tube wall; 3 - layer of wet fibroporous material; 4 - external environment.

\section{Mathematical model}

In the proposed statement, the heat and mass transfer process in the considered decision domain (Fig.

1) in a $1 \mathrm{D}$ formulation is described:

$$
\begin{gathered}
\tau \geq 0, R_{1} \leq r<R_{2} ; \quad c_{2} \rho_{2} \frac{\partial T_{2}}{\partial \tau}=\lambda_{2}\left(\frac{\partial^{2} T_{2}}{\partial r^{2}}+\frac{1}{r} \frac{\partial T_{2}}{\partial r}\right) \\
\tau \geq 0, R_{2}<r \leq R_{3} ; \quad c_{e f}(\tau, r) \rho_{e f}(\tau, r) \frac{\partial T_{3}}{\partial \tau}=\lambda_{e f}(\tau, r)\left(\frac{\partial^{2} T_{3}}{\partial r^{2}}+\frac{1}{r} \frac{\partial T_{3}}{\partial r}\right) \\
\tau=0, R_{1} \leq r \leq R_{3} ; \quad T_{2}=T_{3}=T_{0}=\mathrm{const} ; \\
\tau \geq 0, r=R_{1} ; \quad T_{2}=T_{\text {in }}=\mathrm{const} ; \\
\tau \geq 0, r=R_{2} ; \quad \lambda_{2} \frac{\partial T_{2}}{\partial r}=\lambda_{e f} \frac{\partial T_{3}}{\partial r}-j q ; \quad T_{2}=T_{3} ; \\
\tau \geq 0, r=R_{3} ; \quad-\lambda_{e f}\left(\tau, R_{3}\right) \frac{\partial T_{3}}{\partial r}=\alpha\left(T_{3}-T_{e x}\right) \\
\tau \geq 0, R_{2} \leq r<R_{3} ; \quad \frac{\partial C_{s t}}{\partial \tau}=D_{3}\left(\frac{\partial^{2} C_{s t}}{\partial r^{2}}+\frac{1}{r} \frac{\partial C_{s t}}{\partial r}\right) \\
\tau=0, R_{2} \leq r \leq R_{3} ; \quad C_{s t}=C_{0}=\mathrm{const} ; \\
\tau \geq 0, r=R_{2} ; \quad-D_{3} \rho_{e f}\left(\tau, R_{2}\right) \frac{\partial C_{s t}}{\partial r}=j
\end{gathered}
$$




$$
\tau \geq 0, r=R_{3} ; \quad-D_{3} \frac{\partial C_{s t}}{\partial r}=\beta\left(C_{s t}-C_{e x}\right) .
$$

The mass flux density was determined using the equation from [5]:

$$
j=\frac{a\left(P_{s}-P_{p}\right)}{\sqrt{\frac{2 \pi R_{g}}{M} T\left(\tau, R_{2}\right)}} .
$$

The partial pressure in Eq. (11) was determined by Riedel-Plank-Miller method [7]. The thermophysical properties of insulation at saturation with moisture and steam were determined from the well-known expressions [6] and the effective coefficient of thermal conductivity $\lambda_{e f}-$ by the formula

$$
\lambda_{e f}=\lambda_{3} C_{3}+\lambda_{w} C_{w}+\lambda_{s t} C_{s t},
$$

provided that $C_{3}+C_{w}+C_{s t}=1 ; \quad C_{w}+C_{s t}=f$.

The mass-transfer coefficient was calculated by the formula

$$
\beta=\frac{\alpha}{c_{s t} \rho_{s t}} \text {. }
$$

\section{Method of solution and initial data}

The system of equations (1)-(10) was solved by the finite-difference method [8] using an iterational implicit difference scheme. The characteristic features of the problem solution were the discontinuity of the thermophysical characteristics at the metal tube wall- wet fibroporous material interfaces and the presence of nonlinearity in boundary condition (5).

The analysis was carried out for a pipeline with a diameter of nominal bore of $600 \mathrm{~mm}$; the pipeline was manufactured from steel 10 (thickness $9 \mathrm{~mm}$ ) with thermal insulation from mineral cotton $(70 \mathrm{~mm}$ thick). The value of temperature in the considered region at the initial instant was $T_{0}=298 \mathrm{~K}$. The temperature of the inner surface of the pipe was equal to $T_{i n}=338 ; 363$ and $383 \mathrm{~K}$ and the ambient temperature was $T_{e x}=298 \mathrm{~K}$. The coefficient of heat transfer in all variants of the numerical analysis was $\alpha=11 \mathrm{~W} /\left(\mathrm{m}^{2} \cdot \mathrm{K}\right)$. Initial relative volume concentrations were $C_{w}=f, C_{s t}=0$ and $C_{e x}=0$.

Table 1 contains values of mineral cotton characteristics, which were used in the numerical investigations of thermal conditions of the system under consideration (Fig. 1).

Table 1. Characteristics of mineral cotton

\begin{tabular}{|c|c|c|c|c|c|}
\hline Characteristic & $\lambda_{3},[\mathrm{~W} /(\mathrm{m} \cdot \mathrm{K})]$ & $c_{3},[\mathrm{~kJ} /(\mathrm{kg} \cdot \mathrm{K})]$ & $\rho_{3},\left[\mathrm{~kg} / \mathrm{m}^{3}\right]$ & $D_{3},\left[\mathrm{~m}^{2} / \mathrm{sec}\right]$ & $f$ \\
\hline Value & 0.059 & 0.67 & 206 & $4.5 \cdot 10^{-7}$ & 0.73 \\
\hline
\end{tabular}

\section{Results of numerical simulation}

The main results of numerical modeling of thermal conditions of the system under consideration (Fig. 1) are listed in Table 2 and in Fig. 2.

Validity and reliability of the obtained results follow from tests of the methods for convergence and stability of solutions on multiple meshes, fulfillment of the energy balance conditions at boundaries of the calculation domain, and is also confirmed by comparison of the obtained results and the known experimental [2] and theoretical [1, 5, 6] data obtained by other authors. The relative 


\section{MATEC Web of Conferences}

calculation error in all versions of the numerical analysis did not exceed $0.5 \%$, which is acceptable for investigations of thermal conditions of the system under consideration (Fig. 1).

Table 2 lists the results of numerical experiments of heat fluxes for: dry mineral cotton $\left(Q_{d r y} ;\right)$, wet mineral cotton $\left(Q_{w e t}\right)$, wet mineral cotton considering moisture evaporation $\left(Q_{e v}\right)$ and wet mineral cotton considering evaporation and steam diffusion $\left(Q_{d i f}\right)$.

Table 2. Results of numerical simulation

\begin{tabular}{|c|c|c|c|c|c|c|c|c|c|c|}
\hline 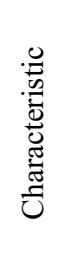 & $\begin{array}{l}T_{i n}, \\
{[\mathrm{~K}]}\end{array}$ & $\begin{array}{c}Q_{d r y}, \\
{[\mathrm{~W} / \mathrm{m}]}\end{array}$ & $\begin{array}{c}Q_{w e t}, \\
{[\mathrm{~W} / \mathrm{m}]}\end{array}$ & $\begin{array}{c}Q_{e v} \\
{[\mathrm{~W} / \mathrm{m}]}\end{array}$ & $\begin{array}{c}Q_{d i f}, \\
{[\mathrm{~W} / \mathrm{m}]}\end{array}$ & 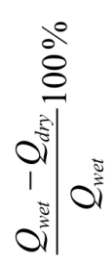 & 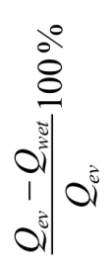 & 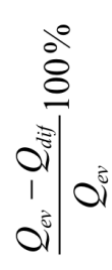 & $\begin{array}{c}80 \\
8 \\
0 \\
0 \\
0 \\
0 \\
0 \\
0 \\
0\end{array}$ & $C_{s t}^{\max }$ \\
\hline \multirow{3}{*}{$\frac{0}{\frac{D}{\pi}}$} & 338 & 68.1 & 387.0 & 430.6 & 414.4 & 82.4 & 10.1 & 3.7 & 83.6 & $\begin{array}{c}0.050 \\
6\end{array}$ \\
\hline & 363 & 110.7 & 639.4 & 845.3 & 794.5 & 82.7 & 24.3 & 6.0 & 86.1 & $\begin{array}{c}0.093 \\
5\end{array}$ \\
\hline & 383 & 144.7 & 842.6 & 1309.1 & 1202.5 & 82.8 & 35.6 & 8.1 & 88.0 & $\begin{array}{c}0.111 \\
2\end{array}$ \\
\hline
\end{tabular}

The numerical experimental results in Table 2 allow us to make the inference about the expected increase of heat fluxes with growing temperature of the internal surface $T_{i n}$.

The data presented in Table 2 allow us to make the following conclusions:

1. The heat flux $Q_{\text {wet }}$ increases by about $80 \%$ compared with the heat flux $Q_{d r y}$.

2. The contribution of steam evaporation to the heat flux $Q_{e v}$ is from 10.1 to $35.6 \%$. Therefore the role of evaporation effect in determining heat fluxes becomes important.

3. The decrease of the heat flux $Q_{d i f}$ explained by existence of steam in wet fibroporous isolation. The reducing of heat flux $Q_{d i f}$ amounts to $8.1 \%$.

The decrease of the heat flux in wet fibroporous material is restricted to values of relative volume concentrations $C_{s t}$. Maximum values of relative volume concentrations in wet fibroporous material $C_{s t}^{\max }$ are shown in Table 2.

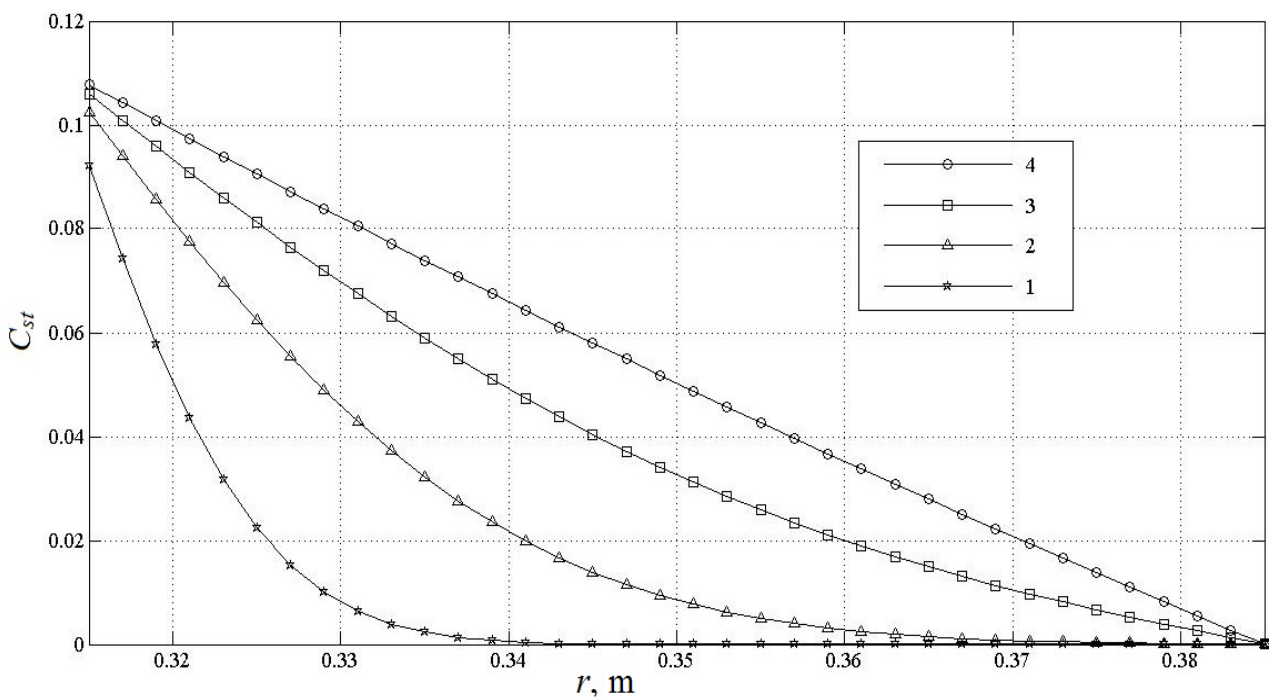

Figure 2. The distributions of relative volume concentrations of steam across the thickness of the wet fibroporous material $\left(T_{i n}=383 \mathrm{~K}\right): 1-0.1 \cdot 10^{3} \mathrm{sec} ; 2-0.5 \cdot 10^{3} \mathrm{sec} ; 3-1.5 \cdot 10^{3} \mathrm{sec} ; 4-5 \cdot 10^{3} \mathrm{sec}$ 
An analysis of nonstationary processes of heat and mass transfer of the system under consideration allow us to make the inference about what time to steady-state condition is $2 \cdot 10^{4} \mathrm{sec}$ and for the diffusion problem $-5 \cdot 10^{3} \mathrm{sec}$. This accords well with results [6]. From analysis of results shown in Fig. 2, it is seen that the process of mass transfer turns out to be nonstationary.

The results of numerical analysis, as presented in Fig. 2, prove that the steady-state condition of the diffusion problem will occur very quickly. This fact is explained by a relatively high diffusion coefficient of mineral cotton (see Table 1).

An analysis of the results listed in Fig. 2 allows one to draw a conclusion that for the heatinsulation materials with a relatively high diffusion coefficient (the mineral or glass cotton), it is possible to neglect the nonstationary process of mass transfer in view of its short duration.

\section{Conclusion}

We have carried out numerical analysis of thermal regimes and numerical analysis of heat fluxes in a wet fibroporous material in conditions of evaporation and steam diffusion. It has been shown that application of the proposed approach enables comprehensive analysis of thermal regimes of the system under consideration.

\section{Acknowledgments}

This work was supported by the Grants Council (under RF President), grant No. MK-1652.2013.8. and by the research state assignment «Science» (Code of Federal Target Scientific and Technical Program 2.1321.2014).

\section{Notations}

$T$ - temperature, $\mathrm{K} ; \tau$ - time, sec; $r$ - current radius, $\mathrm{m} ; R$ - domain boundary, $\mathrm{m} ; \lambda$ - thermal conductivity, $\mathrm{W} /(\mathrm{m} \cdot \mathrm{K}) ; \rho$ - density, $\mathrm{kg} / \mathrm{m}^{3} ; c$ - heat capacity, $\mathrm{J} /(\mathrm{kg} \cdot \mathrm{K}) ; q$ - heat of phase transition, $\mathrm{J} / \mathrm{kg} ; j-$ mass flux density, $\mathrm{kg} /\left(\mathrm{m}^{2} \cdot \mathrm{sec}\right) ; \alpha-$ heat transfer coefficient, $\mathrm{W} /\left(\mathrm{m}^{2} \cdot \mathrm{K}\right) ; D$ - diffusion coefficient, $\mathrm{m}^{2} / \mathrm{sec} ; C$ - relative volume concentration; $\beta$ - mass-transfer coefficient, $\mathrm{m} / \mathrm{sec} ; a-$ accommodation coefficient; $P$ - pressure, $\mathrm{Pa} ; M$ - molecular mass of vapors, $\mathrm{kg} / \mathrm{mole}$; $R_{g}-$ gas constant, $\mathrm{J} /($ mole $\cdot \mathrm{K}) ; f$ - open porosity; $Q$ - heat flux, $\mathrm{W} / \mathrm{m}$.

Indices: 1, 2, and 3 - numbers of calculation domains (Fig. 1); 0 - initial time; ef-effective; in internal; ex - external; st - steam; $w$ - water; $s$ - saturation; $p$ - partial; $d r y$-dry; wet - wet; $e v-$ evaporation; dif-diffusion; $\max$ - maximum.

\section{References}

1. B. Dawoud, M. Imroz Sohel, A. Freni, S. Vasta, G. Restuccia, On the effective thermal conductivity of wetted zeolite under the working conditions of an adsorption chiller, Applied Thermal Engineering. 31 (2011) 2241-2246.

2. A. Abdou, I. Budaiwi, The variation of thermal conductivity of fibrous insulation materials under different levels of moisture content, Construction and Building Materials. 43 (2013) 533-544.

3. J. MacMullen, Z. Zhang, E. Rirsch, H.N. Dhakal, N. Bennett, Brick and mortar treatment by cream emulsion for improved water repellence and thermal insulation, Energy and Buildings. 43 (2011) 1560-1565.

4. V.A.F. Costa, M.L. Mendonca, A.R. Figueiredo, Modeling and simulation of wetted porous thermal barriers operating under high temperature or high heat flux, International Journal of Heat and Mass Transfer. 51 (2008) 3342-3354. 


\section{MATEC Web of Conferences}

5. G.V. Kuznetsov, V.Yu. Polovnikov, Numerical analysis of heat losses by main heat pipelines under conditions of complete or partial flooding, Journal of Engineering Physics and Thermophysics. 81 (2008) 323-331.

6. G.V. Kuznetsov, V.Yu. Polovnikov, Numerical simulation of the thermal state of a flooded pipeline taking into account unsteadiness of the process of heat insulation saturation with moisture, Thermal Engineering. 55 (2008) 426-430.

7. R.C. Reid, J.M. Prausnitz, B.E. Poling, The properties of gases and liquids, McGraw-Hill, New York, 1987.

8. A.L. Garcia, Numerical methods for physics, Prentice Hall, New York, 2000. 